\title{
Comparative efficacy between glimepiride and metformin in preventing progression of prediabetes to type 2 diabetes
}

\author{
Udaya M. Kabadi \\ University of Iowa, Iowa City, USA; ukabadi@gmail.com \\ Received 16 May 2013; revised 18 June 2013; accepted 26 June 2013 \\ Copyright (C) 2013 Udaya M. Kabadi. This is an open access article distributed under the Creative Commons Attribution License, \\ which permits unrestricted use, distribution, and reproduction in any medium, provided the original work is properly cited.
}

\begin{abstract}
Background: Several recent studies have shown that treatment with therapeutic lifestyle changes, and/or several drugs retard progression of prediabetes to type 2 diabetes. However, none of these studies used a Sulfonylurea (SU), although in UKPDS, SUs delayed the progression of hyperglycemia and several subjects would have been categorized as having prediabetes by present diagnostic criteria. Thus, SUs may have delayed the progression in this group as well. Objective: Therefore, we examined comparative efficacy of glimepiride and metformin in progression to diabetes in subjects with prediabetes. Methods: Twenty men and 18 women ages 28 - 81 years with prediabetes were followed for 5 - 9 years. Prediabetes was diagnosed by impaired fasting glucose and $\mathrm{HbA1C}$ between $5.7 \%$ - $6.4 \%$ with two consecutive determinations as recommended by American Diabetes Association. Twenty obese subjects were administered metformin $500 \mathrm{mg} /$ day and 18 non obese subjects received glimepiride $0.5 \mathrm{mg} /$ day, in addition to dietary and exercise counseling. Results: Mean duration of follow up was $5.8 \pm 0.2$ years. Fasting Plasma Glucose (FPG) and HbA1C declined to $<100 \mathrm{mg} / \mathrm{dl}$ and $<5.7 \%$ in all subjects by 6 months. During the follow up period, 9 of 20 $(45 \%)$ subjects receiving metformin and 5 of 18 $(27 \%)$ in glimepiride group progressed to diabetes $(p<0.01)$ as determined by FPG $\geq 126$ $\mathrm{mg} / \mathrm{dl}$ and $\mathrm{HbA1C} \geq 6.5 \%$ (RR, 1.61 with Confidence Interval, 1.43 - 1.74 for metformin vs glimepiride; $p<0.01$ ). The mean duration to progression was $32 \pm 4$ months in metformin
\end{abstract}

*The data was presented in part at the meeting of International Diabetes Federation in Dubai in December 2011. group and $47 \pm 5$ months in subjects receiving glimepiride. FPG and HbA1c levels promptly returned to $<100 \mathrm{mg} / \mathrm{dl}$ and $<5.7 \%$ on increasing daily dose of both metformin $(1000-1500 \mathrm{mg})$ and glimepiride (2-4 mg). The glycemic control was maintained till the end of observation period. None of the subjects in either group manifested a cardiovascular event nor any of the subjects died during the period of observation. Conclusion: Glimepiride may be more effective in delaying the progression of prediabetes to diabetes in non-obese subjects in comparison to metformin in obese subjects with no significant difference in cardiovascular morbidity or overall mortality.

Keywords: Type 2 Diabetes Pharmacotherapy; CVD/Lipids/Insulin Resistance; Prediabetes

\section{INTRODUCTION}

Several studies using therapeutic lifestyle interventions [1-8] have delayed the progression of prediabetes (impaired fasting glucose and impaired glucose tolerance) to type 2 diabetes as defined by diagnostic criteria established by American Diabetes Association [9]. Similarly, several recent reports described delaying progression of prediabetes to type 2 diabetes with use of drugs approved for treatment of hyperglycemia in subjects with type 2 diabetes including metformin, acarbose, voglibose, rosiglitazone and pioglitazone $[2,10-16]$. Finally, in UKPDS, sulfonylureas, e.g. glibenclamide and chlorpropamide delayed the worsening of hyperglycemia in subjects with type 2 diabetes as well $[17,18]$. However, several subjects in this study were in the stage of "prediabetes" by the present criteria established by American Diabetes association [1] for diagnosis of diabetes (fasting plasma glucose $\geq 126 \mathrm{mg} / \mathrm{dl}$ ) since subjects were categorized as 
having diabetes based on fasting plasma glucose level of $>110 \mathrm{mg} / \mathrm{dl}[19,20]$. Moreover, tolbutamide, 1st generation SU was reported to be effective in prevention of progression of impaired glucose tolerance to type 2 diabetes in short term study over the duration of 1 year and over a 10 year period in another long term study $[21,22]$. None of the newer sulfonylurea agents have been well tested for prevention or delay of progression from prediabetes to diabetes although glimepiride appeared to delay progression in a recent study with results barely missing attaining a statistical significance [23]. The lack of significant improvement may be attributed probably to subjects in the study being obese in whom presence of insulin resistance is a major contributing factor [24]. In contrast occurrence of prediabetes and diabetes in non obese subjects is mainly attributed to the decline in insulin secretion [24]. Therefore, we addressed the efficacy of glimepiride, a long acting sulfonylurea for delaying progression to diabetes in non obese subjects with prediabetes and compared it with well proven efficacy of metformin in obese subjects with prediabetes.

\section{SUBJECTS AND METHODS}

Body weight, glycemic control (fasting plasma glucose and $\mathrm{HbA1C}$ levels) and comprehensive metabolic panels were recorded at intervals of $3-6$ months for 5 - 9 years in 20 men and 18 women, ages $28-81$ years with prediabetes. The diagnosis of prediabetes was based on fasting plasma glucose between $100-125 \mathrm{mg} / \mathrm{dl}$ and HbA1C between $5.7 \%-6.4 \%$ on two consecutive determinations. Obese subjects with BMI over $30 \mathrm{~kg} / \mathrm{m}^{2}$ were administered metformin in a daily dose of $500 \mathrm{mg}$ because the major contributing factor to prediabtetes and diabetes in obese subjects is insulin resistance whereas glimepiride, $0.5 \mathrm{mg}$ was chosen in the remaining non obese subjects with the BMI $\leq 27 \mathrm{~kg} / \mathrm{m}^{2}$ because the decline in insulin secretion has been documented to play a major role in inducing prediabetes and diabetes in this group [24]. Nutritional and exercise counseling was conducted at yearly intervals. Progression to type $2 \mathrm{DM}$ was defined as increase in fasting plasma glucose $>125$ $\mathrm{mg} / \mathrm{dl}$ and/or a rise in $\mathrm{HbAlc}$ above $6.4 \%$ requiring increased dosage of metformin or glimepiride to regain normal glycemic control (fasting plasma glucose $<100$ $\mathrm{mg} / \mathrm{dl}$ and $\mathrm{HbAlc}<5.7 \%$ ).

\section{RESULTS}

Fasting plasma glucose and $\mathrm{HbA1C}$ concentrations declined within 6 months individually as well as a group following treatment with either metformin or glimepiride [Table 1]. Hypoglycemic symptoms or FPG $\leq 70 \mathrm{mg} / \mathrm{dl}$ were not reported in either of the groups. In metformin group, 9 of 20 subjects progressed to type 2 DM between
24 - 35 months whereas the progression was noted in 5 of 18 glimepiride treated subjects between $37-48$ months. In all these subjects, normal glycemic control was restored by increasing the daily dose of metformin and glimepiride respectively (Table 2). In subjects not progressing to type $2 \mathrm{DM}$, eleven $(55 \%)$ in metformin group and 13 [73\%] in glimepiride group, both fasting plasma glucose and $\mathrm{HbA1C}$ remained within normal range, $<100 \mathrm{mg} / \mathrm{dl}$ and $<5.7 \%$ respectively by the end of period of observation. None of the subjects in either treatment group manifested a cardiovascular events nor any subject died during the period of observation.

\section{DISCUSSION}

This study demonstrates that glimepiride delays progression of prediabetes to diabetes as defined by criteria, the fasting plasma glucose and $\mathrm{HbA} 1 \mathrm{C}$ concentrations in a significantly higher number of subjects as compared to subjects treated with metformin $(\mathrm{P}<0.01)$. Moreover, the time to progression in glimepiride group was also significantly longer compared to subjects treated with metformin. [P $<0.01]$ Similar observations have been documented with use of tolbutamide, a 1st generation sulfonylurea $[21,22]$. A similar efficacy of chlorpropamide and glibenclamide in delaying the progression to type 2 DM was also probably evident in UKPDS since several subjects in this study belonged to the present "prediabetes" state since the criteria used for diagnosis of diabetes was fasting plasma glucose concentration of

Table 1. Fasting plasma glucose (FPG) and HbAlc in subjects prior to (Pre) and at the end of 6 months following (Post) therapy $(\mathrm{Rx})$.

\begin{tabular}{ccc}
\hline Subjects & FPG mg/dl & HbA1c \% \\
\hline Metformin PreRx & $118 \pm 3$ & $6.1 \pm 0.2$ \\
Metformin Post Rx & $94 \pm 2^{*}$ & $5.4 \pm 0.1^{*}$ \\
Glimepiride Pre Rx & $116 \pm 4$ & $6.2 \pm 0.2$ \\
Glimepiride Post Rx & $95 \pm 3^{*}$ & $5.5 \pm 0.1^{*}$ \\
\hline
\end{tabular}

${ }^{*} \mathrm{p}<0.01$ vs Pre Rx.

Table 2. Efficacy of metformin (obese) and glimepiride (nonobese) in delaying progression from pre-diabetes to type $2 \mathrm{DM}$.

\begin{tabular}{cccc}
\hline & $\begin{array}{c}\text { Metformin } \\
500 \mathrm{mg}\end{array}$ & $\begin{array}{c}\text { Glimepiride } \\
0.5 \mathrm{mg}\end{array}$ & $\mathrm{p}$ Value \\
\hline $\begin{array}{c}\text { Number of } \\
\text { Subjects }\end{array}$ & $9 / 20$ & $5 / 18$ & $\mathrm{RR} 1.61$ \\
(CI, $1.43-1.74)^{*}$ \\
$\begin{array}{c}\text { Duration at } \\
\text { Progression } \\
\text { (Months) }\end{array}$ & $30 \pm 3$ & $27 \%$ & $<01$ \\
\hline
\end{tabular}

${ }^{*}$ Confidence interval. 
over $110 \mathrm{mg} / \mathrm{dl}$ [17-20]. However, this finding is in contrast to a recent European study [23] in which glimepiride reduced the progression from the stage of impaired fasting glucose to type 2 diabetes in 41 of 136 subjects $(30 \%)$ in comparison to 55 of 138 subjects (40\%) administered placebo although the difference was not statistically significant $(\mathrm{p}=0.072)$. Several factors may have contributed to the different outcomes between our study and this report. Longer duration of follow up period of 9 years in our study in comparison to this report with duration of 5 years may have contributed to the difference in the pattern of progression. Alternatively, the difference in population of subjects between these studies may be an important contributor to different results. Our study included subjects with diagnostic criteria for diagnosis of prediabetes as defined by both the fasting plasma glucose $(100-125 \mathrm{mg} / \mathrm{dl})$ and HbAlc $(5.7 \%$ $6.4 \%$ ) whereas the participants in the other study were classified as "Impaired fasting glucose" with no documentation of HbA1c levels. Moreover, Glimepiride was used only in lean subjects in our study in contrast to overweight and obese subjects in the other report. We firmly believe that glucose dysregulation in lean subjects with prediabetes is primarily induced by declining insulin secretion whereas rising insulin resistance is the main contributor to impaired glucose metabolism in obese subjects [24]. Therefore, glimepiride with its main effect on improving both 1 st and second phase insulin secretion [25-28] is distinctly likely to be more effective in lean subjects with prediabetes as noted in our study in comparison to the obese subjects in the other report.

Declining B cell function is a major contributor to pathogenesis in the onset of diabetes as documented in several studies [29-35]. Moreover, impaired glucose tolerance and impaired fasting glucose are attributed to inhibited 1 st and 2 nd phases of insulin secretion following a meal respectively [26,29-35]. Therefore, the drug such as glimepiride which enhances both 1 st and second phase insulin secretion is likely to initiate improvement in both fasting and postprandial glycemic excursions and delay progression from prediabetes to diabetes. Alternately, the efficacy of glimepiride in improving insulin sensitivity, al be it, much less compared to metformin and glitazones has also been reported in several studies [28,36-39]. Moreover, normalization of impaired glucose regulation achieved in the short term appears to delay progression to diabetes over a long term period as is documented recently in DPP 2 in USA [8]. Finally, it is imperative that the term "delay in progression from prediabetes" is more appropriate than the term "prevention of type 2 diabetes" since progression from prediabetes to type 2 diabetes following withdrawal of drugs resumed at the same rate as was noted in subjects administered placebo [40-44]. Therefore, we believe that glimepiride may be useful as yet another therapeutic option in delaying the progression of prediabetes towards diabetes especially in non obese subjects in whom the decline in beta cell function is a more prominent physiologic aberration in contrast to obese subjects characterized by major contribution by rising insulin resistance to glucose dysregulation. Finally, it is apparent that it is as effective as metformin in terms of ensuing cardiovascular outcomes as well as overall mortality. However, in both obese and non obese subjects with prediabetes, both the declines in insulin secretion and insulin sensitivity are contributory factors. Therefore, although glimepiride may improve both these abnormalities, its combination with metformin, a distinctly more effective agent to ameliorate insulin resistance may be more effective in delaying progression of prediabetes to diabetes for even a longer duration than that observed with individual agent in all subjects irespective of the body weight. Moreover, the daily dosage of these agents required to achieve the objective may be smaller than when used as a monotherapy resulting in lesser side effects as well.

The major limitation of the study is the small number of subjects as well as the lack of observation on the effect of discontinuation of drugs on progression from prediabetes to diabetes. Therefore, a similar study as well as a study using both drugs in combination recruiting a large population of obese and non obese subjects with prediabetes may be useful in further examination of our observation.

\section{REFERENCES}

[1] Eriksson, K.F. and Lindgärde, F, (1991) Prevention of type 2 (non-insulin-dependent) diabetes mellitus by diet and physical exercise. The 6-year Malmö feasibility study. Diabetologia, 34, 891-898. doi:10.1007/BF00400196

[2] Pan, X.R., Li, G.W., Hu, Y.H., et al. (1997) Effects of diet and exercise in preventing NIDDM in people with impaired glucose tolerance. The Da Qing IGT and diabetes study. Diabetes Care, 20, 537-544. doi:10.2337/diacare.20.4.537

[3] Tuomilehto, J., Lindström, J., Eriksson, J.G., et al. (2001) Prevention of type 2 diabetes mellitus by changes in lifestyle among subjects with impaired glucose tolerance. The New England Journal of Medicine, 344, 1343-1350. doi:10.1056/NEJM200105033441801

[4] Knowler, W.C., Barrett-Connor, E., Fowler, S.E., et al. (2002) Reduction in the incidence of type 2 diabetes with lifestyle intervention or metformin. The New England Journal of Medicine, 346, 393-403. doi:10.1056/NEJMoa012512

[5] Ramachandran, A., Snehalatha, C., Mary, S., et al. 2006 The Indian Diabetes Prevention Programme shows that lifestyle modification and metformin prevent type 2 diabetes in Asian Indian subjects with impaired glucose tolerance (IDPP-1). Diabetologia, 49, 289-297. 
doi:10.1007/s00125-005-0097-Z

[6] Perreault, L., Kahn, S.E., Christophi, C.A., et al. (2009) Regression from pre-diabetes to normal glucose regulation in the diabetes prevention program. Diabetes Care, 32, 1583-1588. doi:10.2337/dc09-0523

[7] Saaristo, T., Moilanen, L., Korpi-Hyövälti, E., et al. (2010) Lifestyle intervention for prevention of type 2 diabetes in primary health care: One-year follow-up of the Finnish National Diabetes Prevention Program (FIN-D2D). Diabetes Care, 33, 2146-2151. doi:10.2337/dc10-0410

[8] Perreault, L., Pan, Q., Mather, K.J., et al. (2012) Effect of regression from prediabetes to normal glucose regulation on long-term reduction in diabetes risk: Results from the Diabetes Prevention Program Outcomes Study. Lancet, 379, 2243-2251. doi:10.1016/S0140-6736(12)60525-X

[9] American Diabetes Association (2012) Standards of medical care in diabetes-2012. Diabetes Care, 35, S11S63. doi:10.2337/dc12-s011

[10] Chiasson, J.L., Josse, R.G., Gomis, R., et al. (2002) Acarbose for prevention of type 2 diabetes mellitus: The STOP-NIDDM randomised trial. Lancet, 359, 2072-2077.

[11] Kawamori, R., Tajima, N., Iwamoto, Y., et al. (2009) Voglibose for prevention of type 2 diabetes mellitus: A randomised, double-blind trial in Japanese individuals with impaired glucose tolerance. Lancet, 373, 1607-1614. doi:10.1016/S0140-6736(09)60222-1

[12] DREAM (Diabetes REduction Assessment with Ramipril and Rosiglitazone Medication) Trial Investigators, Gerstein, H.C., Yusuf, S., Bosch, J., et al. (2006) Effect of rosiglitazone on the frequency of diabetes in patients with impaired glucose tolerance or impaired fasting glucose: A randomised controlled trial. Lancet, 368, 1096-1105. doi:10.1016/S0140-6736(06)69420-8

[13] NAVIGATOR Study Group (2010) Effect of valsartan on the incidence of diabetes and cardiovascular events. The New England Journal of Medicine, 362, 1477-1490. doi:10.1056/NEJMoa1001121

[14] Zinman, B., Harris, S.B., Neuman, J., et al. (2010) Lowdose combination therapy with rosiglitazone and metformin to prevent type 2 diabetes mellitus (CANOE trial): A double-blind randomised controlled study. Lancet, 376, 103-111. doi:10.1016/S0140-6736(10)60746-5

[15] DeFronzo, R.A., Tripathy, D., Schwenke, D.C., et al. (2011) Pioglitazone for diabetes prevention in impaired glucose tolerance. The New England Journal of Medicine, 364, 1104-1115. doi:10.1056/NEJMoa1010949

[16] Faghihimani, E., Aminorroaya, A., Rezvanian, H., et al. (2012) Salsalate reduces insulin resistance and plasma glucose level in persons with prediabetes. Endocrine Practice, 11, 1-17.

[17] UK Prospective Diabetes Study (UKPDS) Group (1998) Intensive blood-glucose control with sulphonylureas or insulin compared with conventional treatment and risk of complications in patients with type 2 diabetes (UKPDS 33). Lancet, 352, 837-853. doi:10.1016/S0140-6736(98)07019-6

[18] UK Prospective Diabetes Study (UKPDS) Group (1998) Effect of intensive blood-glucose control with metformin on complications in overweight patients with type 2 diabetes (UKPDS 34). Lancet, 352, 854-865. doi:10.1016/S0140-6736(98)07037-8

[19] Colagiuri, S., Cull, C.A., Holman, R.R., et al. (2002) Are lower fasting plasma glucose levels at diagnosis of type 2 diabetes associated with improved outcomes? UK prospective diabetes study 61. Diabetes Care, 25, 1410-1417. doi: $10.2337 /$ diacare.25.8.1410

[20] Kabadi, U.M. (2002) United Kingdom prospective diabetes study: A different perspective. Endocrine Practice, 8 , 61-64. doi:10.4158/EP.8.1.61

[21] Karunakaran, S., Hammersley, M.S., Morris, R.J., et al. (1997) The Fasting Hyperglycaemia Study: III. Randomized controlled trial of sulfonylurea therapy in subjects with increased but not diabetic fasting plasma glucose. Metabolism, 46, 56-60. doi:10.1016/S0026-0495(97)90319-X

[22] Sartor, G., Scherstén, B., Carlström, S., et al.(1980) Tenyear follow-up of subjects with impaired glucose tolerance: Prevention of diabetes by tolbutamide and diet regulation. Diabetes, 29, 41-49. doi:10.2337/diabetes.29.1.41

[23] Lindblad, U., Lindberg, G., Månsson, N.O., et al. (2011) Can sulphonylurea addition to lifestyle changes help to delay diabetes development in subjects with impaired fasting glucose? The Nepi ANtidiabetes studY (NANSY). Diabetes, Obesity and Metabolism, 13, 185-188. doi:10.1111/j.1463-1326.2010.01331.x

[24] Alvarsson, M., Wajngot, A., Cerasi, E., et al. (2005) $\mathrm{K}$-value and low insulin secretion in a non-obese white population: Predicted glucose tolerance after 25 years. Diabetologia, 48, 2262-2268. doi:10.1007/s00125-005-1929-6

[25] Sonnenberg, G.E., Garg, D.C., Weidler, D.J., et al. (1997) Short-term comparison of once- versus twice-daily administration of glimepiride in patients with non-insulindependent diabetes mellitus. The Annals of Pharmacotherapy, 31, 671-676.

[26] Korytkowski, M., Thomas, A., Reid, L., et al. (2002) Glimepiride improves both first and second phases of insulin secretion in type 2 diabetes. Diabetes Care, 25, 16071611. doi:10.2337/diacare.25.9.1607

[27] Singh, J., Unnikrishnan, A.G., Agrawal, N.K., et al. (2002) Immunoreactive insulin response to a single dose of glimepiride in lean type 2 diabetic subjects. Journal of the Association of Physicians of India, 50, 1232-1235.

[28] Kabadi, M.U. and Kabadi, U.M. (2004) Effects of glimepiride on insulin secretion and sensitivity in patients with recently diagnosed type 2 diabetes mellitus. Clinical Therapeutics, 26, 63-69. doi:10.1016/S0149-2918(04)90006-9

[29] Bruce, D.G., Chisholm, D.J., Storlien, L.H., et al. (1988) Physiological importance of deficiency in early prandial insulin secretion in non-insulin dependent diabetes. Diabetes, 37, 736-744. doi:10.2337/diabetes.37.6.736

[30] Mitrakou, A., Kelley. D., Mokan, M., et al. (1992) Role of reduced suppression of glucose production and diminished early insulin release in impaired glucose tolerance. 
The New England Journal of Medicine, 326, 22-29. doi:10.1056/NEJM199201023260104

[31] Van Haeften, T.W., Pimenta, W., Mitrakou, A., et al. (2000) Relative contributions of beta-cell function and tissue insulin sensitivity to fasting and postglucose-load glycemia. Metabolism, 49, 1318-1325. doi:10.1053/meta.2000.9526

[32] UK Prospective Diabetes Study Group (1995) UK prospective diabetes study 16 . Overview of 6 years' therapy of type II diabetes: A progressive disease. Diabetes, 44, 1249-1258. Erratum in: Diabetes, 45, 1655. doi:10.2337/diabetes.44.11.1249

[33] Pratley, R.E. and Weyer, C. (2001) The role of impaired early insulin secretion in the pathogenesis of Type II diabetes mellitus. Diabetologia, 44, 929-945. doi: $10.1007 / \mathrm{s} 001250100580$

[34] Kabadi, U.M. and Kabadi, M.U. (2011) Early postprandial Insulin secretion: Its relation to Insulin sensitivity, Journal of Diabetes Mellitus, 1, 1-5. doi:10.4236/jdm.2011.11001

[35] DeFronzo, R.A. and Abdul-Ghani, M.A. (2011) Preservation of beta-cell function: The key to diabetes prevention. The Journal of Clinical Endocrinology \& Metabolism, 96, 2354-2366. doi:10.1210/jc.2011-0246

[36] Müller, G., Satoh, Y. and Geisen, K. (1995) Extrapancreatic effects of sulfonylureas-A comparison between glimepiride and conventional sulfonylureas. Diabetes Research and Clinical Practice, 28, S115-S137. doi:10.1016/0168-8227(95)01089-V

[37] Müller, G. and Geisen, K. (1996) Characterization of the molecular mode of action of the sulfonylurea, glimepiride, at adipocytes. Hormone and Metabolic Research, 28, 469-487. doi:10.1055/s-2007-979839

[38] Eckel, J. (1996) Direct effects of glimepiride on protein expression of cardiac glucose transporters. Hormone and Metabolic Research, 28, 508-511. doi:10.1055/s-2007-979842

[39] Kabadi, M.U. and Kabadi, U.M. (2003) Efficacy of sulfonylureas with insulin in type 2 diabetes mellitus. Annals of Pharmacotherapy, 37, 1572-1576. doi:10.1345/aph.1C492

[40] Melander, A. (1996) Review of previous impaired glucose tolerance intervention studies. Diabetic Medicine, 13, S20-S22.

[41] Melander, A. (1998) Pharmacological intervention: The antidiabetic approach. European Journal of Clinical Investigation, $\mathbf{2 8}, 23-25$.

doi:10.1046/j.1365-2362.1998.0280s2023.x

[42] Faerch, K., Borch-Johnsen, K., Holst, J.J., et al. (2009) Pathophysiology and aetiology of impaired fasting glycaemia and impaired glucose tolerance: Does it matter for prevention and treatment of type 2 diabetes? Diabetologia, 52, 1714-1723. doi:10.1007/s00125-009-1443-3

[43] DREAM Trial Investigators (2011) Incidence of diabetes following ramipril or rosiglitazone withdrawal. Diabetes Care, 34, 1265-1269. doi:10.2337/dc10-1567

[44] Armato, J., DeFronzo, R.A., Abdul-Ghani, M., et al. (2012) Successful treatment of prediabetes in clinical practice: Targeting insulin resistance and $\beta$-cell dysfunction. Endocrine Practice, 18, 342-350. doi:10.4158/EP11194.OR 